\title{
THE SUPERCAM INFRARED \\ INSTRUMENT ON THE NASA MARS2020 MISSION \\ Performance and qualification results
}

J.-M. Reess ${ }^{1}$, M. Bonafous ${ }^{1}$, L. Lapauw², O. Humeau ${ }^{2}$, T. Fouchet ${ }^{1}$, P. Bernardi ${ }^{1}$, Ph. Cais ${ }^{3}$, M. Deleuze ${ }^{6}$, O. Forni ${ }^{4}$, S. Maurice $^{4}$; S. Robinson ${ }^{5}$, R.C. Wiens ${ }^{5}$, and the SuperCam Team

${ }^{1}$ LESIA, Observatoire de Paris, PSL, CNRS, Sorbonne Université, Univ. Paris Diderot, Sorbonne Paris Cité, France, ${ }^{2}$ LATMOS, Université Versailles Saint-Quentin, 11 boulevard d'Alembert, 78280 Guyancourt, ${ }^{3}$ Univ. Bordeaux, LAB, UMR 5804, F-33615, Pessac, France, CNRS, LAB, UMR 5804, F-33615, Pessac, France, ${ }^{4}$ IRAP, 14, avenue Edouard Belin, 31400 Toulouse, France, ${ }^{5}$ Los Alamos National Laboratory P.O. Box 1663, Los Alamos, NM 87545, USA, ${ }^{6}$ CNES, 18, avenue Edouard Belin, 31401 Toulouse cedex 4, France 


\section{Science overview (I)}

\section{EVOLVING SCIENCE STRATEGIES FOR MARS EXPLORATION}

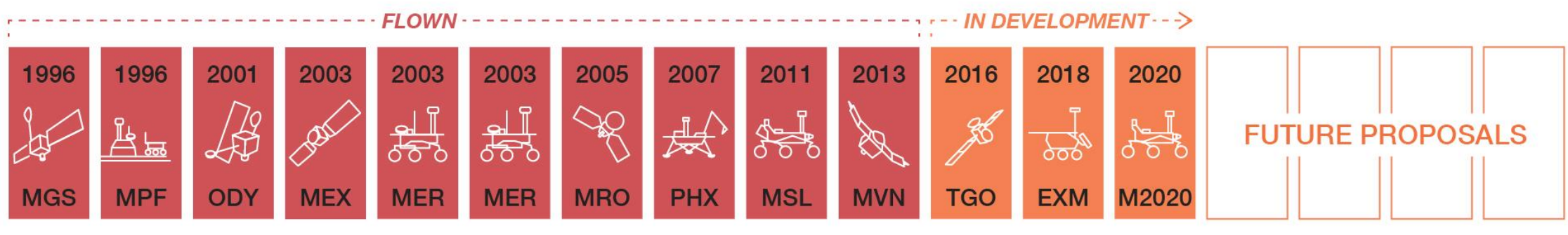

FOLLOW THE WATER

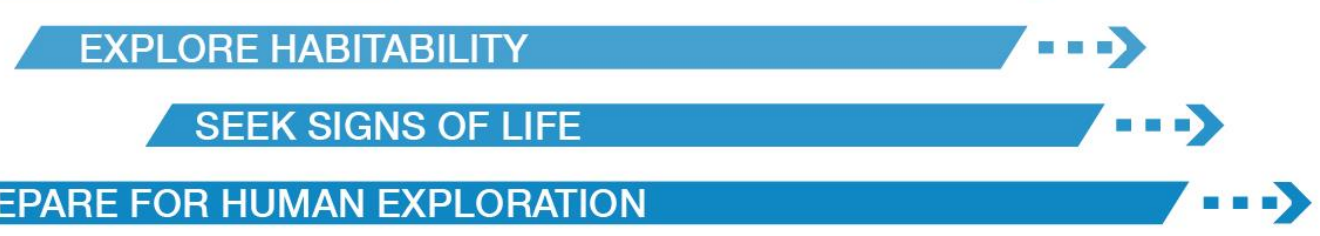

With also

Mangalyaan

Insight (2016) 


\section{Science overview (II)}

\section{Mars 2020 science goals}

- Formation and evolution of geological structures

- In situ astrobiology

- Caching (selection and stock for a potential sample return)

- Prepare Mars exploration

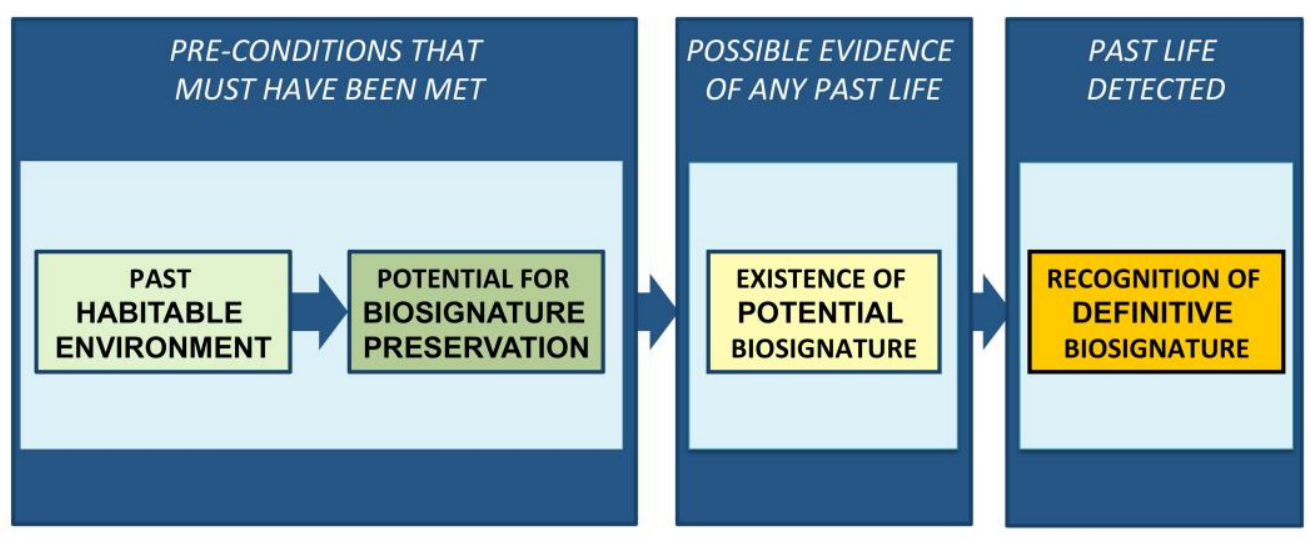

Proposed Mars 2020 Rover 


\section{SuperCam overview}
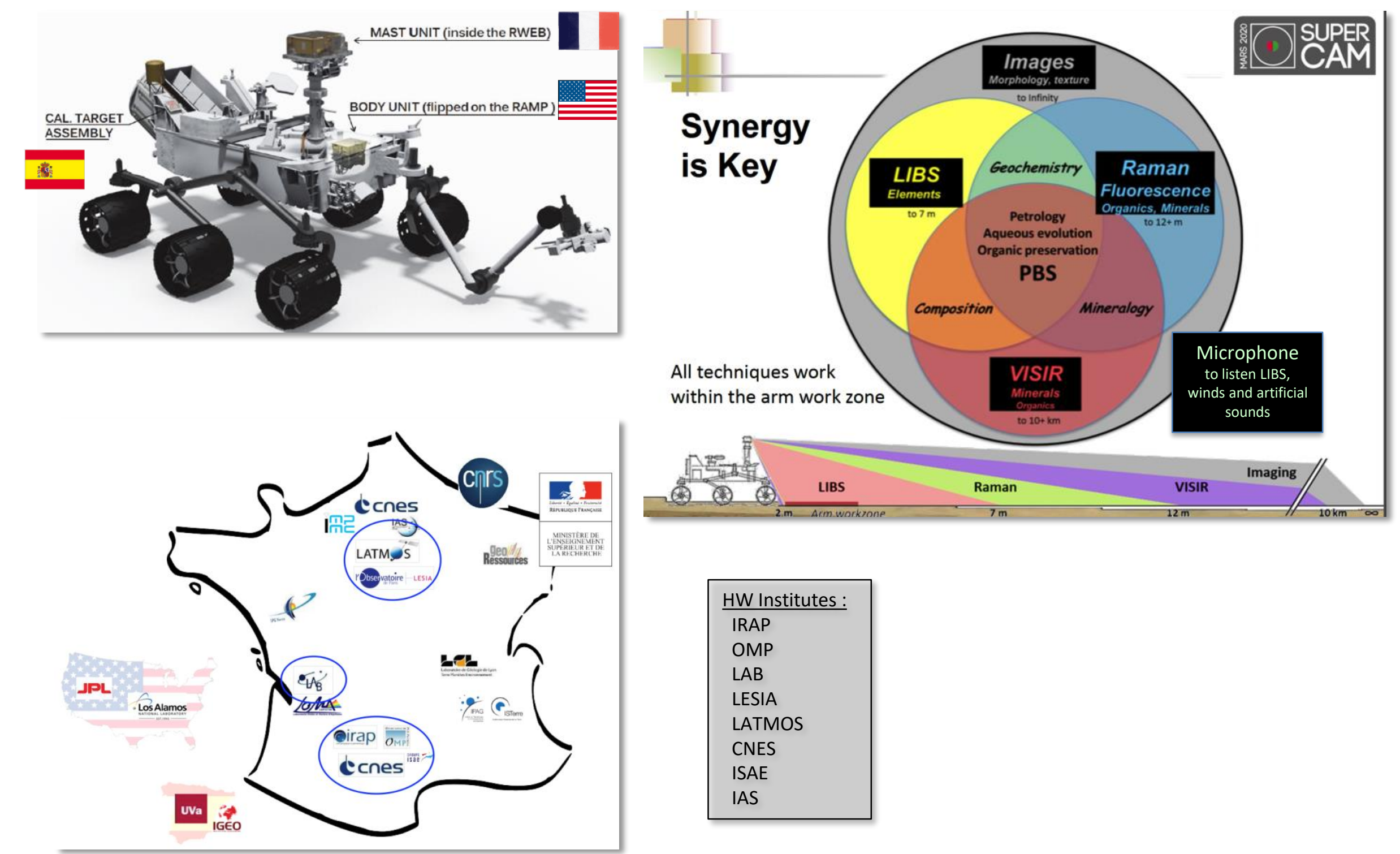

\begin{tabular}{l}
\hline HW Institutes: \\
\hline IRAP \\
OMP \\
LAB \\
LESIA \\
LATMOS \\
CNES \\
ISAE \\
IAS
\end{tabular}




\section{SuperCam}
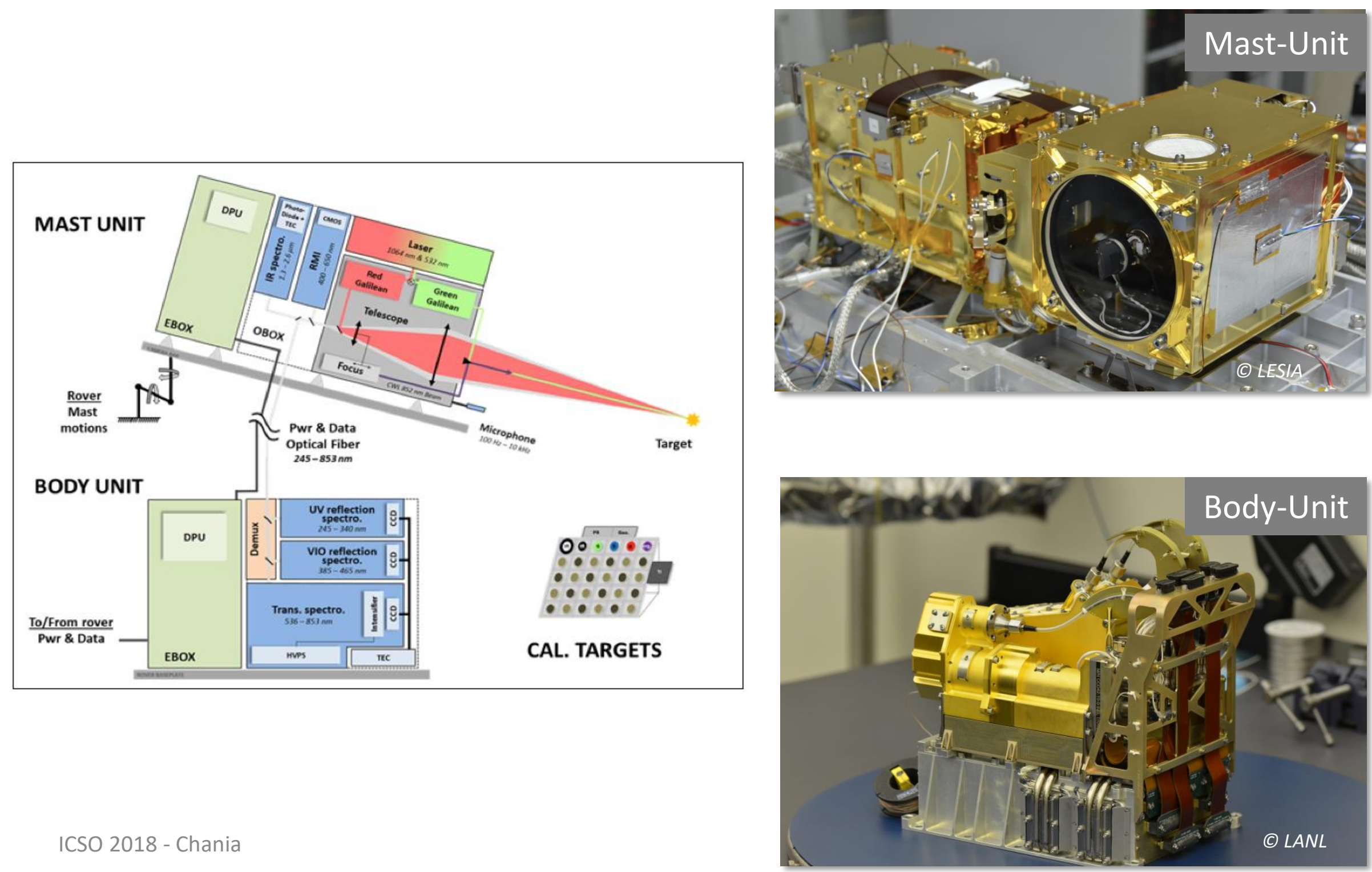


\section{Requirement overview}

\section{IR spectroscopy}

- Wavelength range [1.3-2.6] $\mu \mathrm{m}$

- Bandpass (AOTF FWHM) < 32cm-1 (11.4nm @ $1.95 \mu \mathrm{m})$

- FOV: $1.15 \mathrm{mrad}$

- Resolving power: $170 @ 1.95 \mu \mathrm{m}$

- Sampling: $15 \mathrm{~cm}-1$

- Number of spectral samples: 256 max

- SNR higher than 60 with the spectrometer colder than $-5^{\circ} \mathrm{C}$ in a maximum $80 \mathrm{~s}$ integration time for the acquisition of 86 spectels

\section{RAMAN and fluorescence spectroscopy}

- Wavelength range [536-750]nm

- Spectral resolution: $12 \mathrm{~cm}-1$

- FOV: 0.8mrad

\section{LIBS}

- Wavelength range [245-853]nm

- Spectral resolution better than $0.65 \mathrm{~nm}$

- FOV: $0.8 \mathrm{mrad}$

\section{VIS spectroscopy}

- Wavelength range [400-853]nm

- Spectral resolution better than $0.65 \mathrm{~nm}$

- FOV: $0.8 \mathrm{mrad}$

\section{Imaging}

- Wavelength range [400-750]nm

- RGB imaging

- $F O V>15 \mathrm{mrad}$

- Spatial resolution $<80 \mu \mathrm{rad}$

\section{Microphone}

- Acoustic signal range: $100 \mathrm{~Hz}$ to $10 \mathrm{kHz}$ 


\section{MU optical design}

\section{Emission}
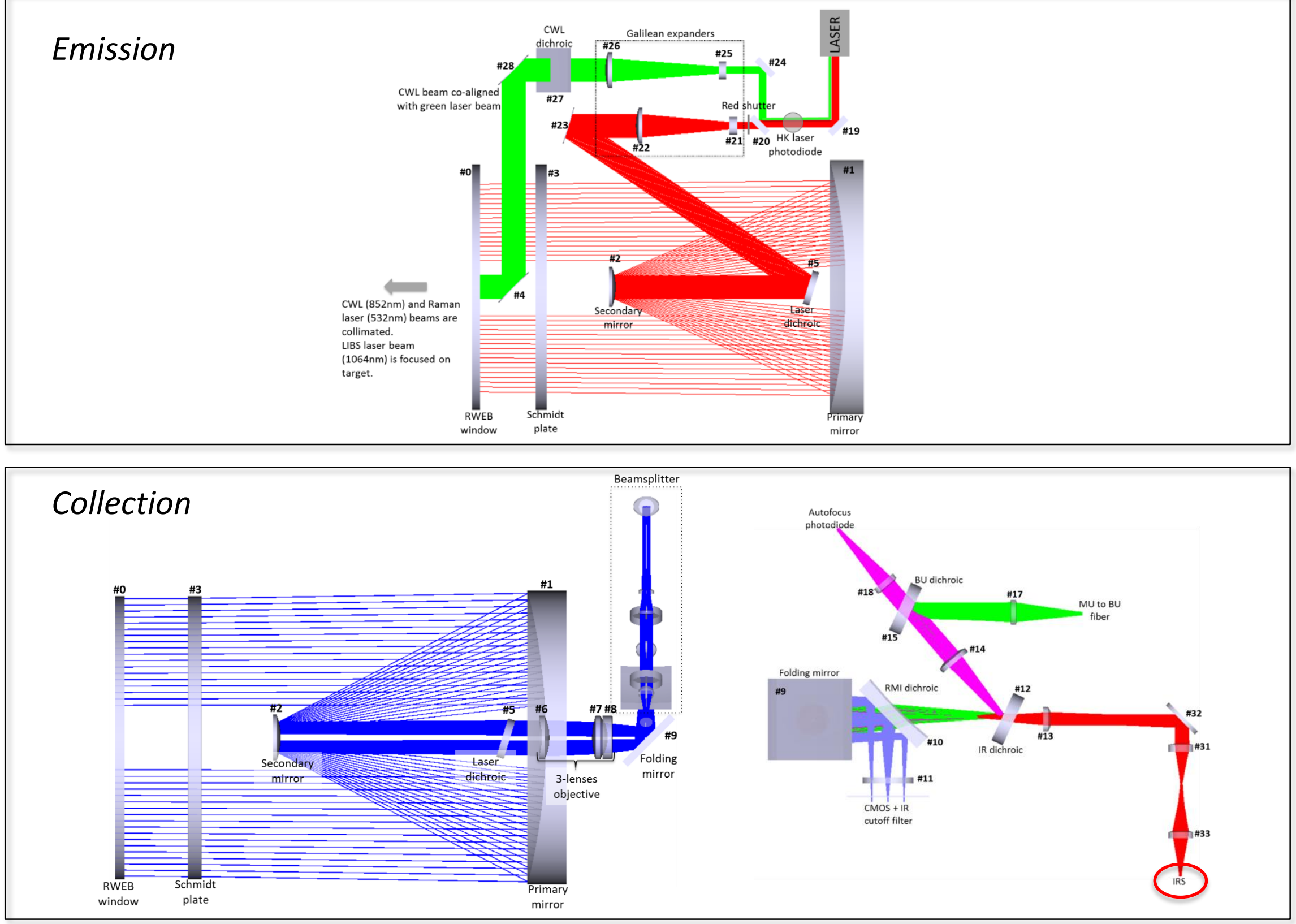


\section{MU design overview}
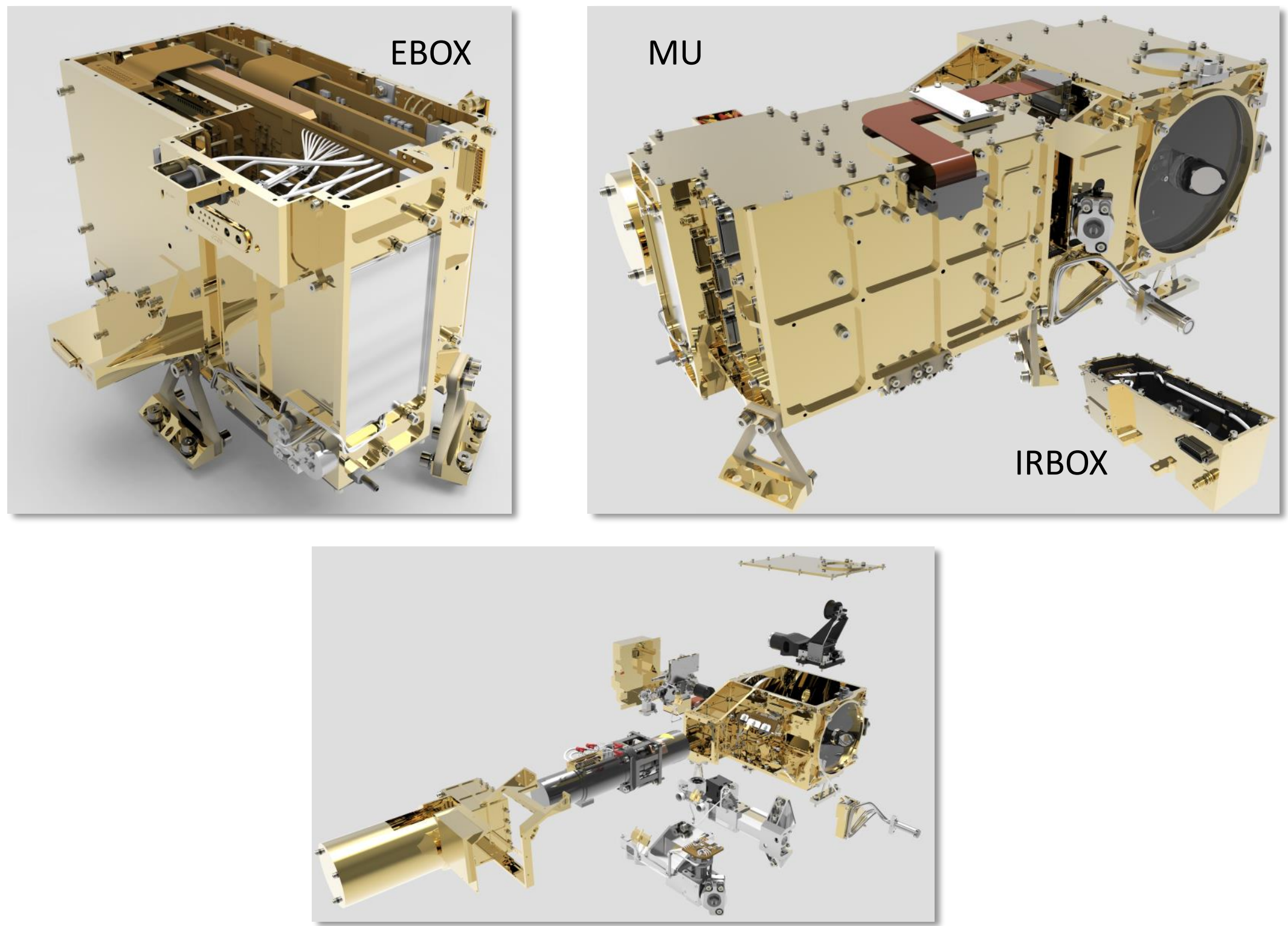


\section{IR spectrometer optical design}

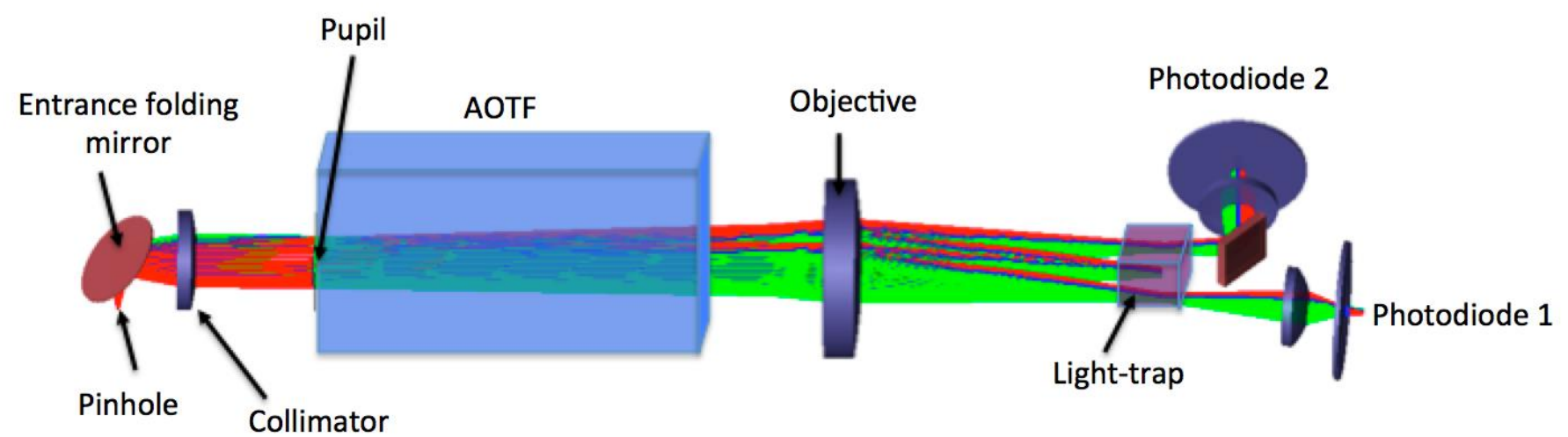

\section{AOTF requirement}

- $\quad$ Provider: Gooch and Housego (UK)

- Wavelength tuning $1300 \mathrm{~nm}<\lambda<2600 \mathrm{~nm}$

- Drive frequency range $30 \mathrm{MHz}<\mathrm{f}<80 \mathrm{MHz}$

- Maximum RF drive power $3.5 \mathrm{~W}$

- Bandpass resolution $\mathrm{d} \lambda \sim 11.5 \mathrm{~nm} @ \lambda=1950 \mathrm{~nm}$

- O-ray and e-ray are imaged on 2 photodiodes

- Pointing stability over the tuning range to be \pm 3 mrad for both o-ray and e-ray

- Order 0 is 500 times brighter than e-ray and o-ray. It is trapped in a PNC black coated light-trap (TIS $<3.5 \%)$

\section{Photodiodes requirement}

- Commercial Judson/Teledyne J19 photodiode

- $\quad 1 \mathrm{~mm}$ MCT chip

- 3 stage TEC, max power to get max DT < $1.5 \mathrm{~W}$, time constant $<30$ s to get max DT $\left(\sim 80^{\circ}\right)$

- $\quad$ Screening and LAT program for qualification

\section{Spectrometer}

- Dimensions: $(173 \times 52 \times 62) \mathrm{mm}$

- Mass: 401g (IRBOX) + 109g (IRBOARD) 


\section{Infrared spectrometer overview}
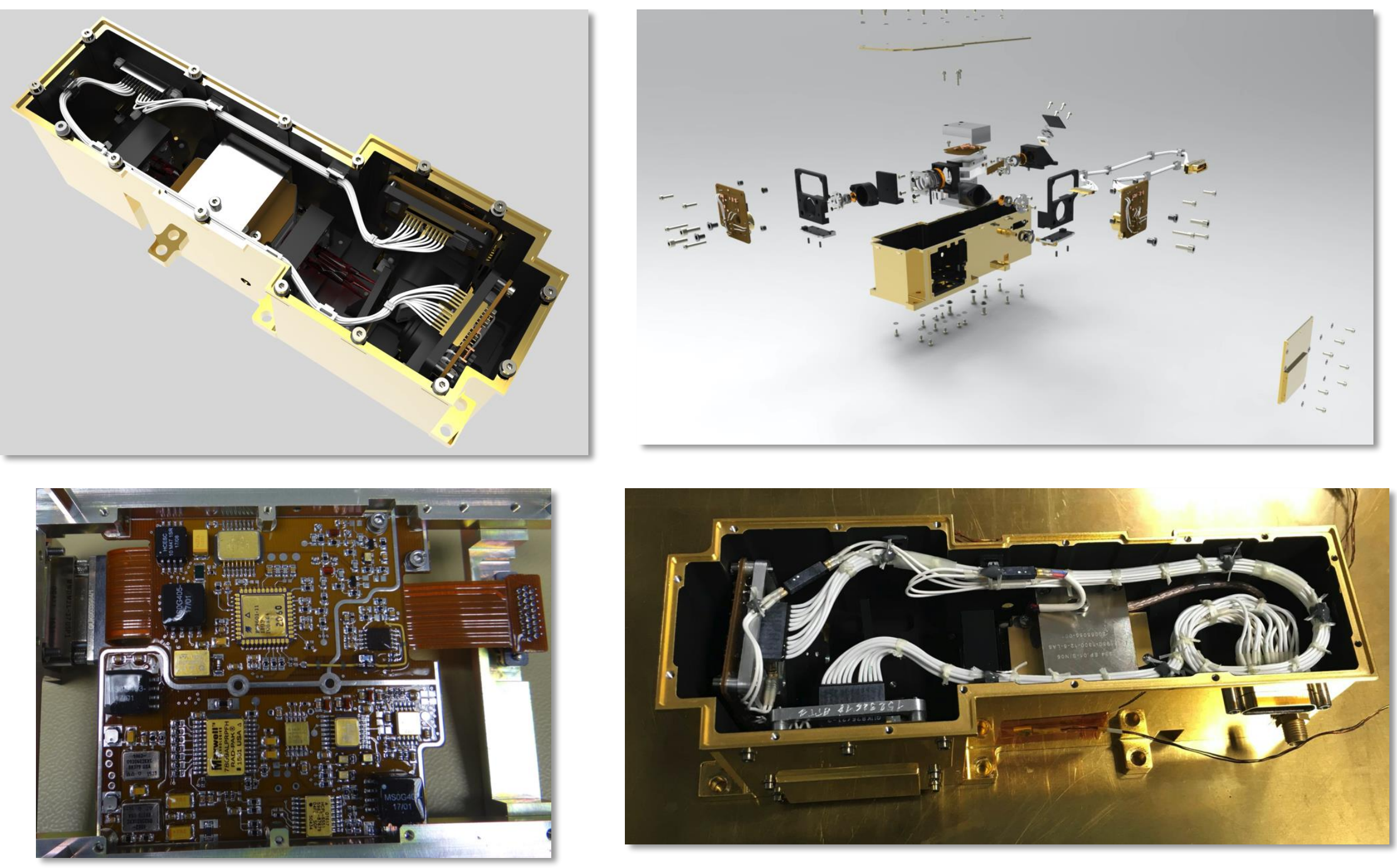

ICSO 2018 - Chania 


\section{Instrument development}

- EDU

- First model to tests the optical functions (no performance)

- Used at JPL for rover control command testing

- STM

- Mechanical and thermal model for environment testing (no optics)

- EQM

- Performance tests and qualification at MU and BU levels

- MU and BU coupled for performance tests

- $\mathrm{FM}$

- Subsystems such as IR spectrometer passed successfully flight acceptance tests

- First coupling at MU level in August 2018

- Plan for delivery: end 2018
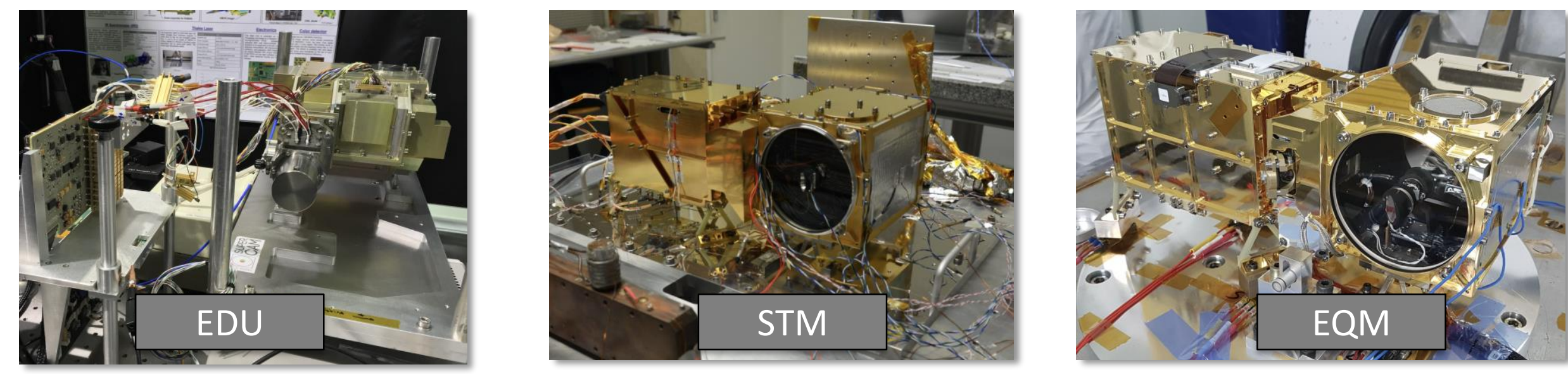


\section{Infrared spectrometer FM test flow}
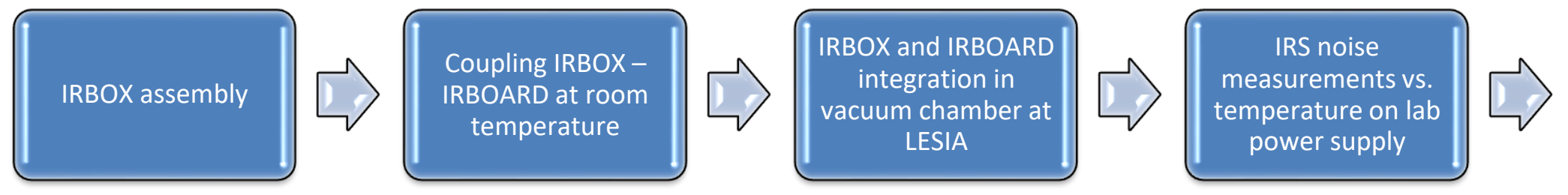

IRBOX coupling to MU at Toulouse

IRS optical measurement vs temperature
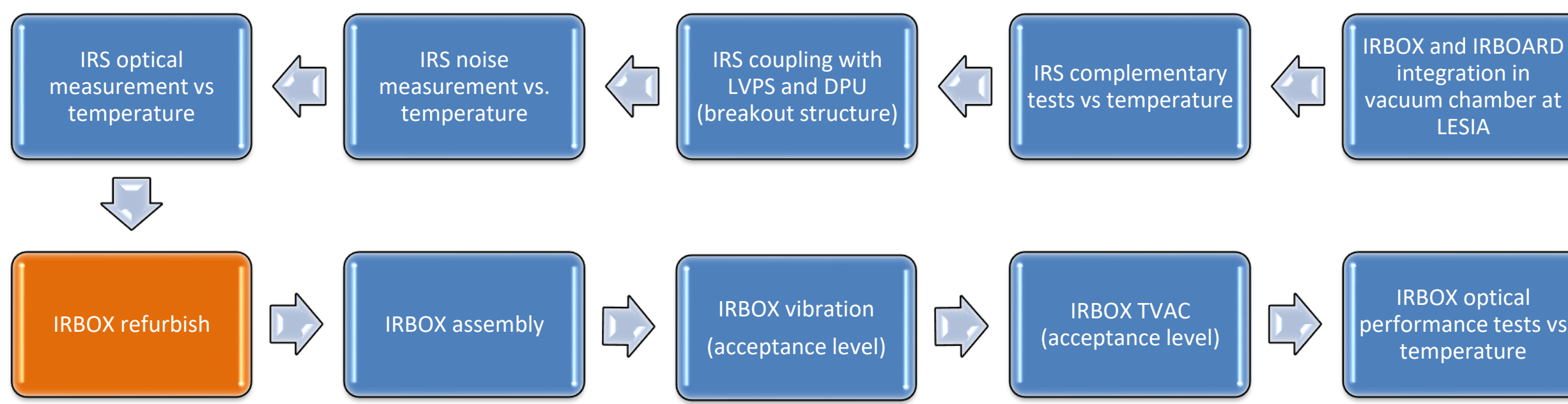

\section{$18 / 07 / 2018$}
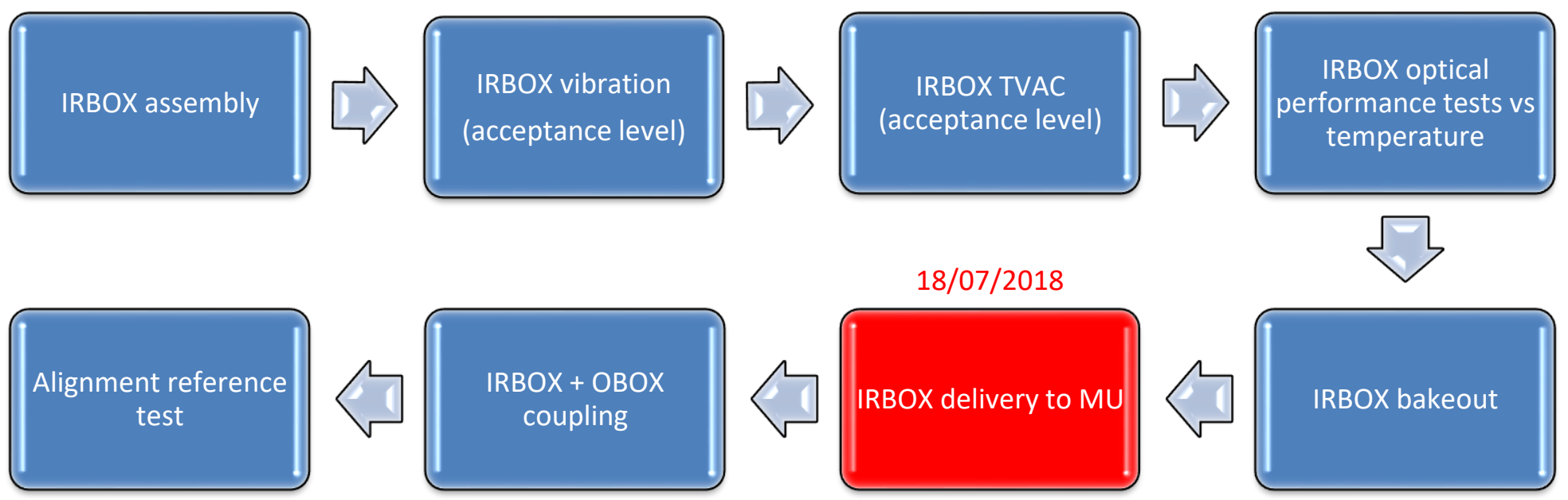


\section{Infrared spectrometer measurements}
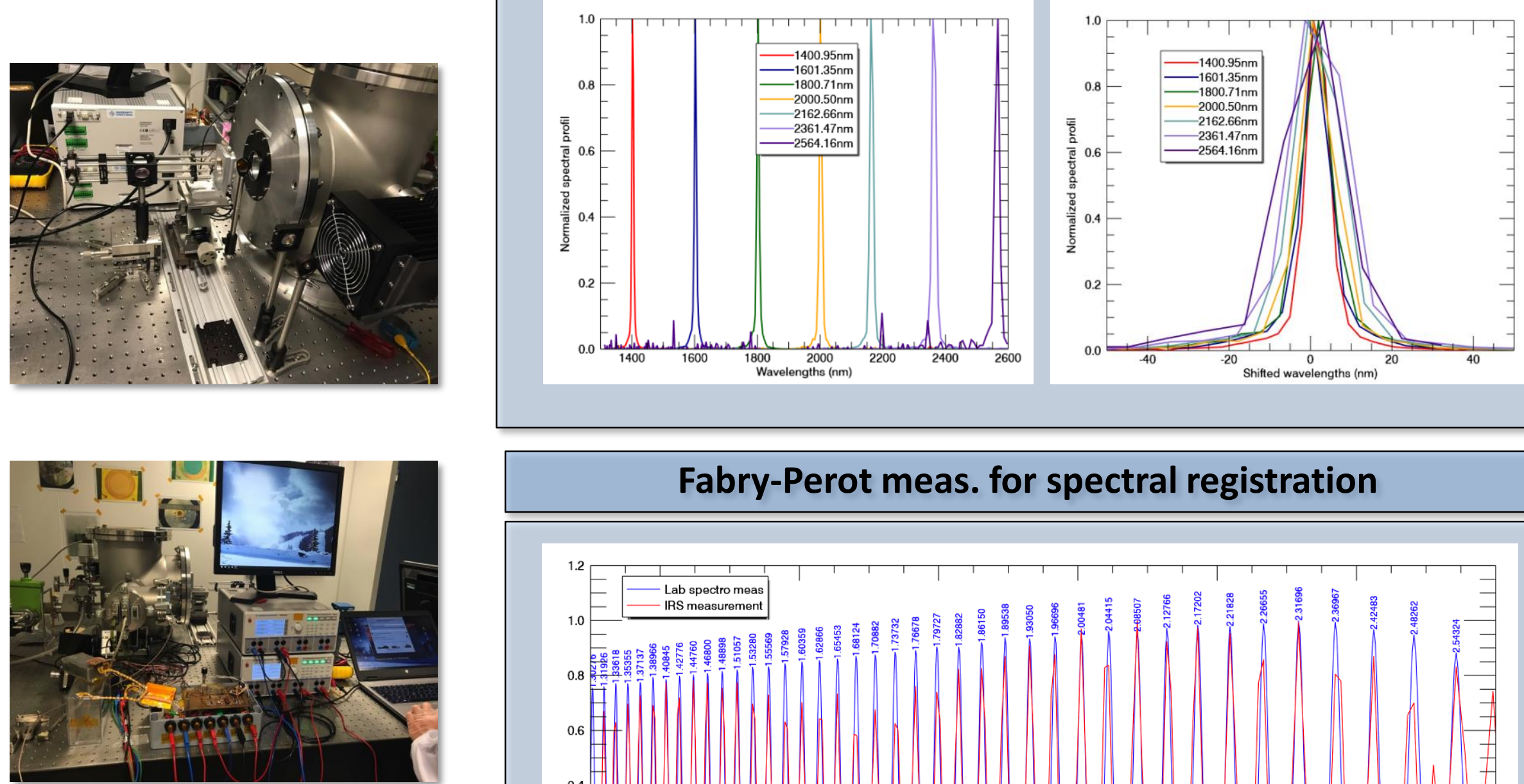

Fabry-Perot meas. for spectral registration

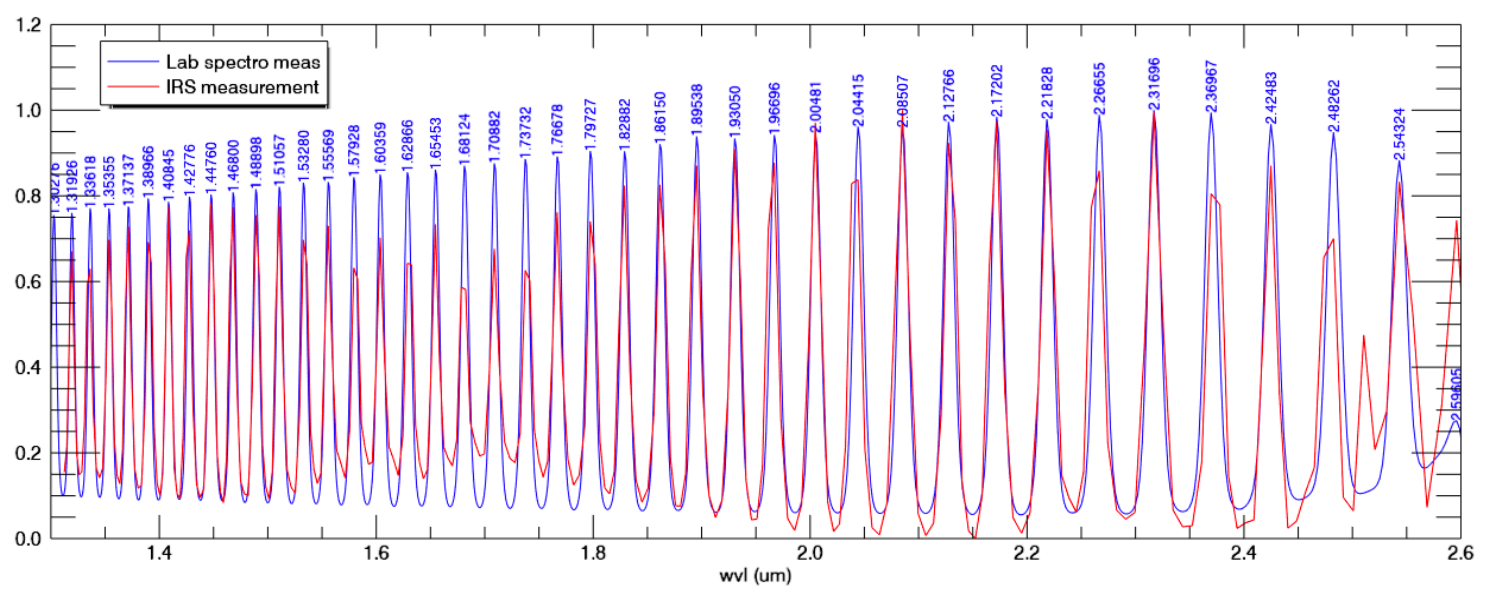




\section{Infrared spectrometer performance}
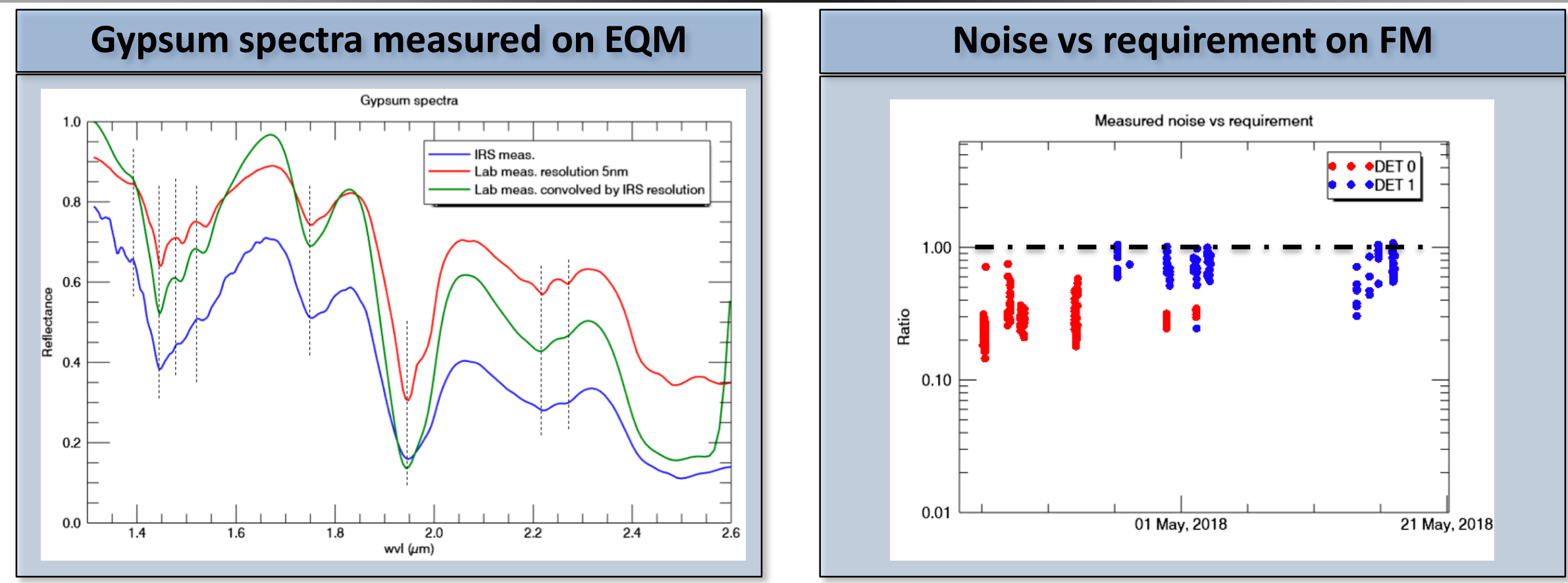

Spectral resolution measured on FM

Relative registration measured on FM
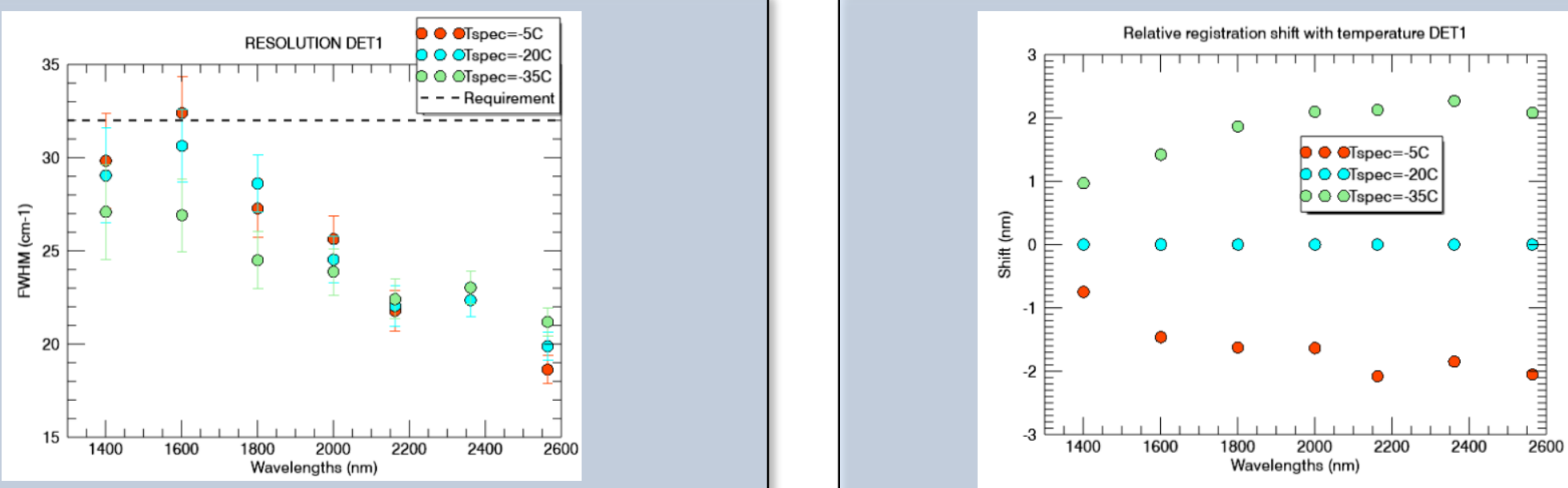


\section{Conclusion}

- After environment tests the infrared spectrometer meets its requirements and has been delivered to $\mathrm{MU}$

- FM MU reference tests are done before environment tests. Global performance are OK.

- In December MU will go through radiometric calibration of the infrared spectroscopy

- FM MU will be delivered at the end of the year to LANL for end-to-end characterization

- SuperCam delivery to JPL in spring 2019 